SUPPLEMENTARY FIGURE 2
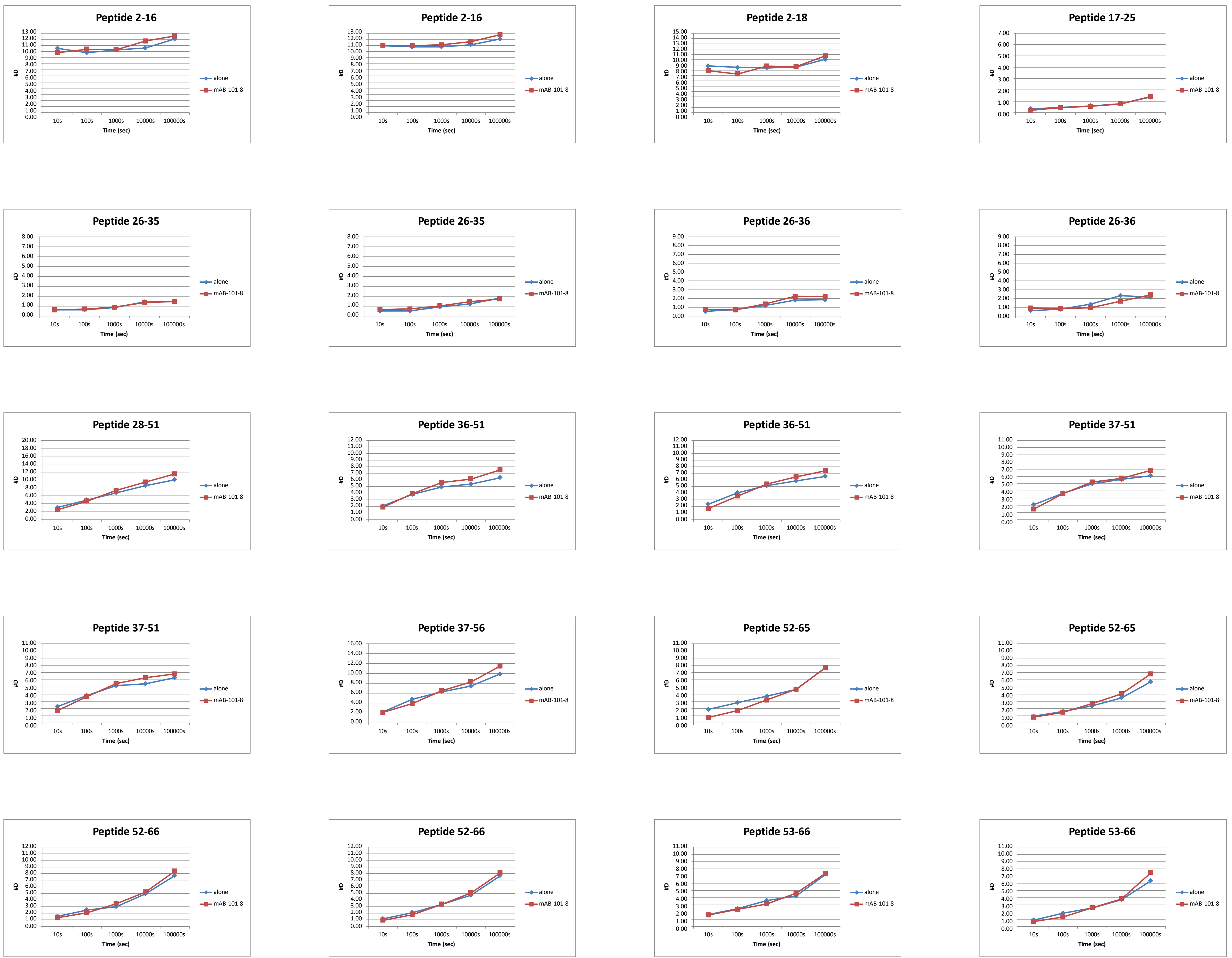


\section{SUPPLEMENTARY FIGURE 2 (CONTINUED)}
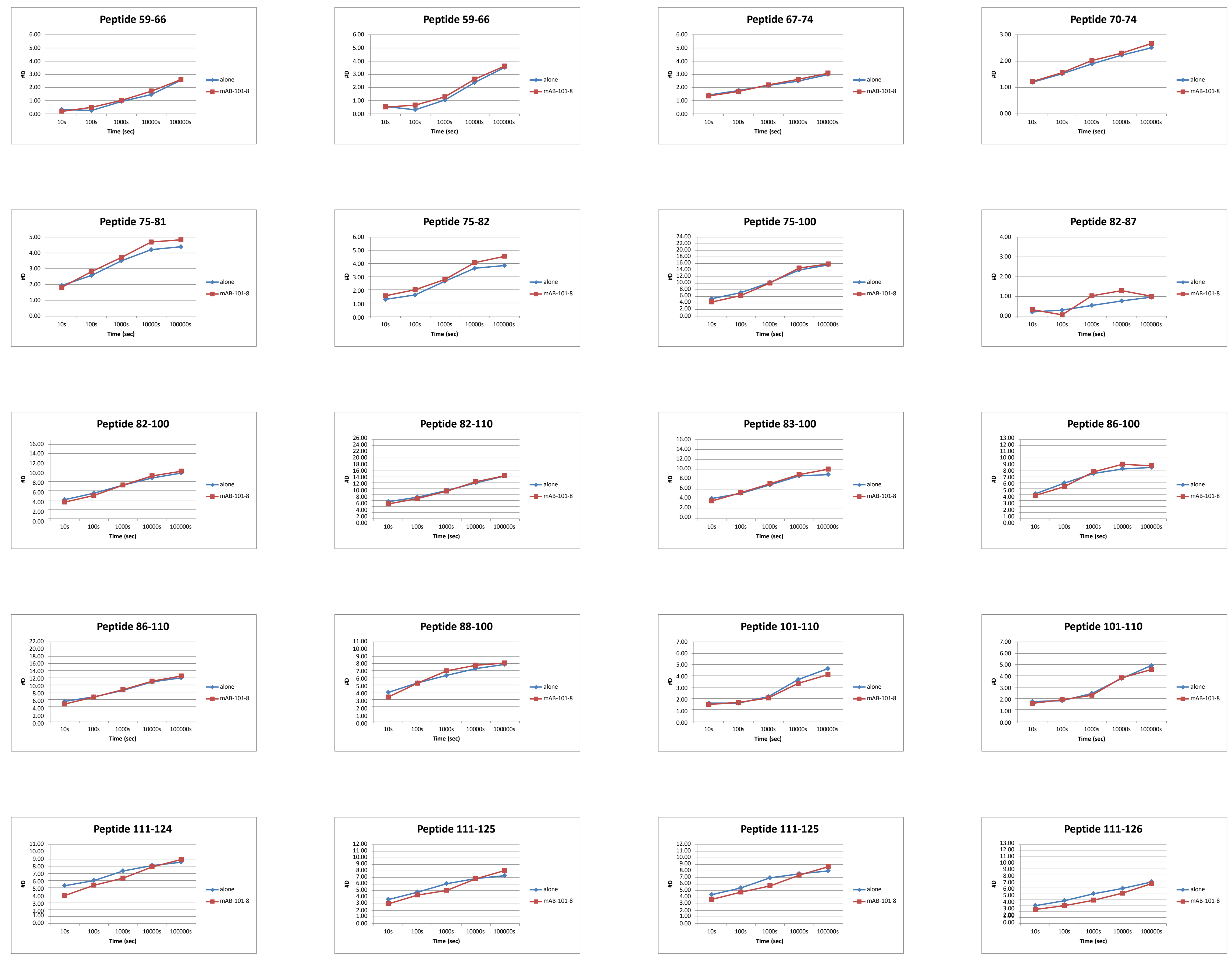

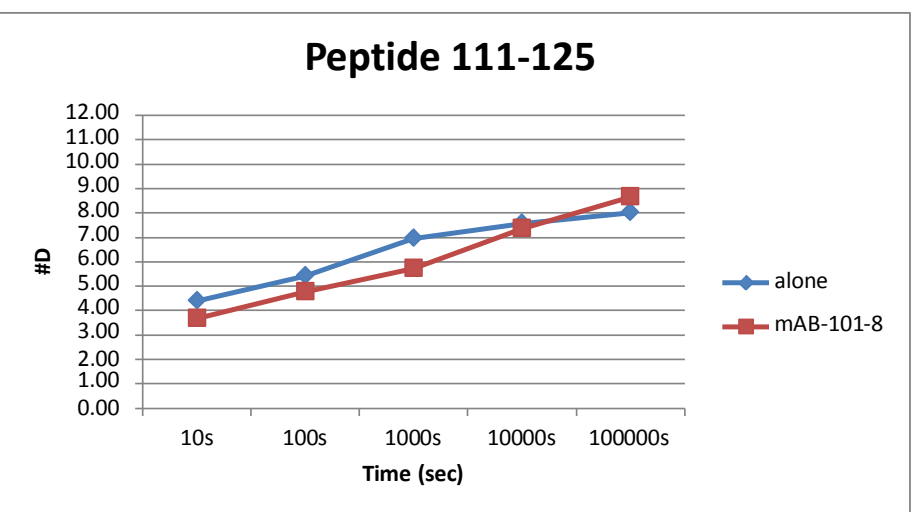




\section{SUPPLEMENTARY FIGURE 2 (CONTINUED)}
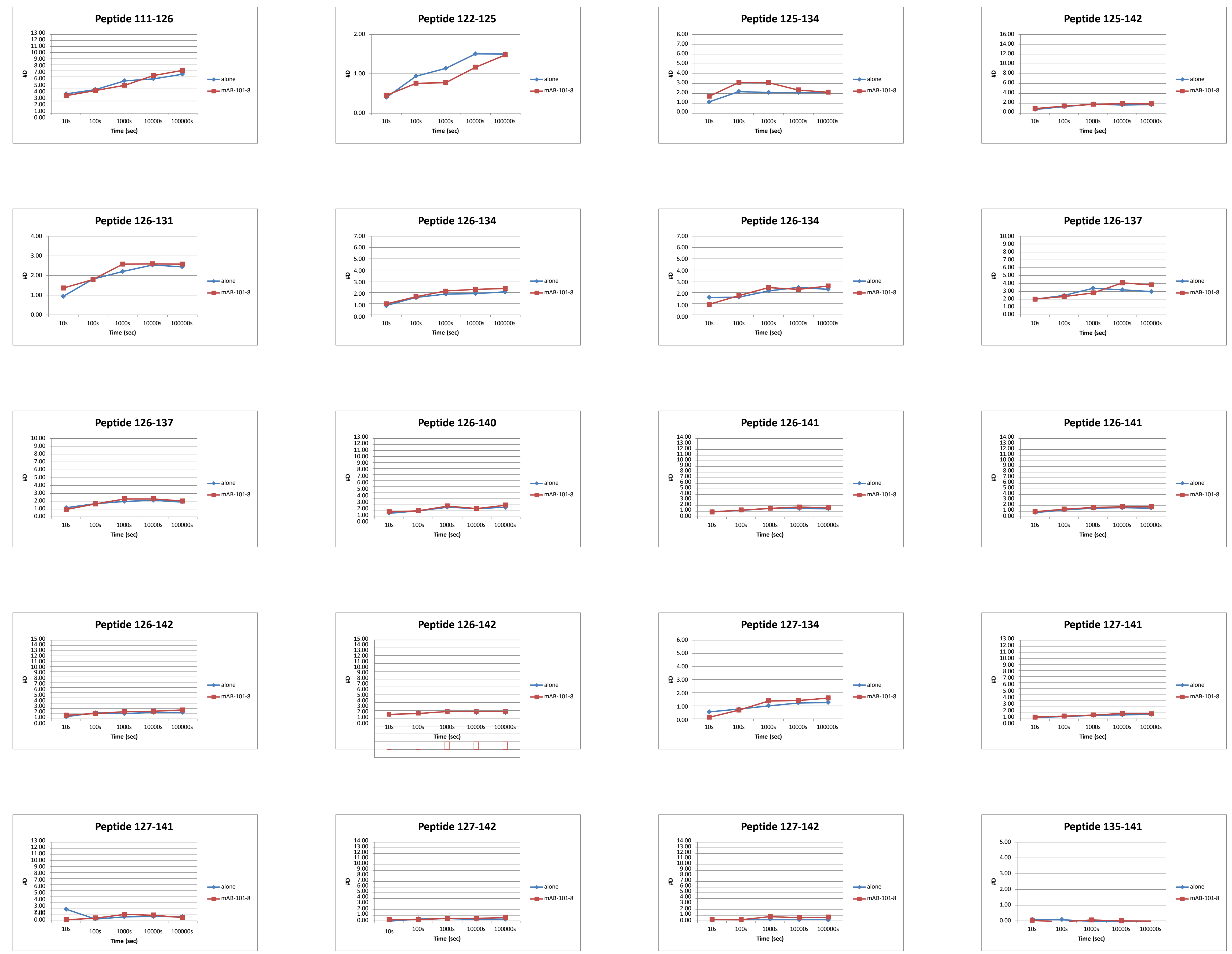

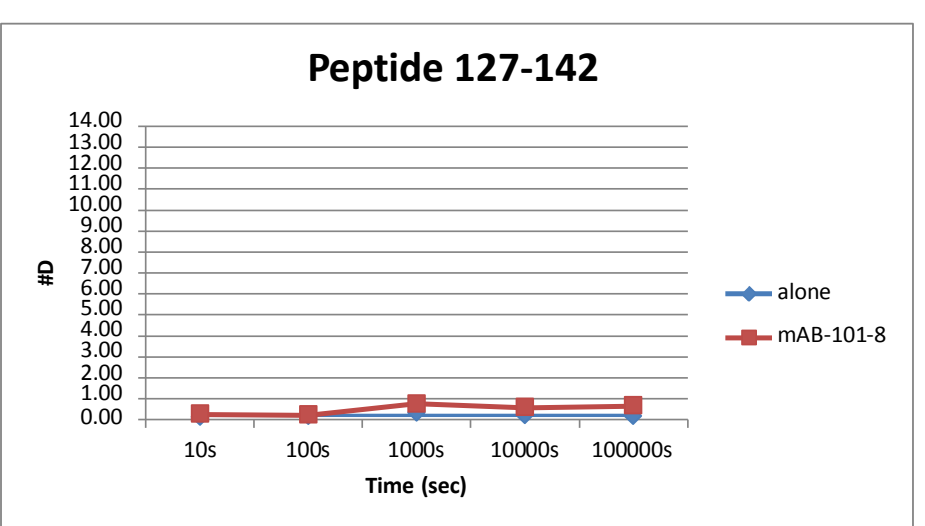




\section{SUPPLEMENTARY FIGURE 2 (CONTINUED)}
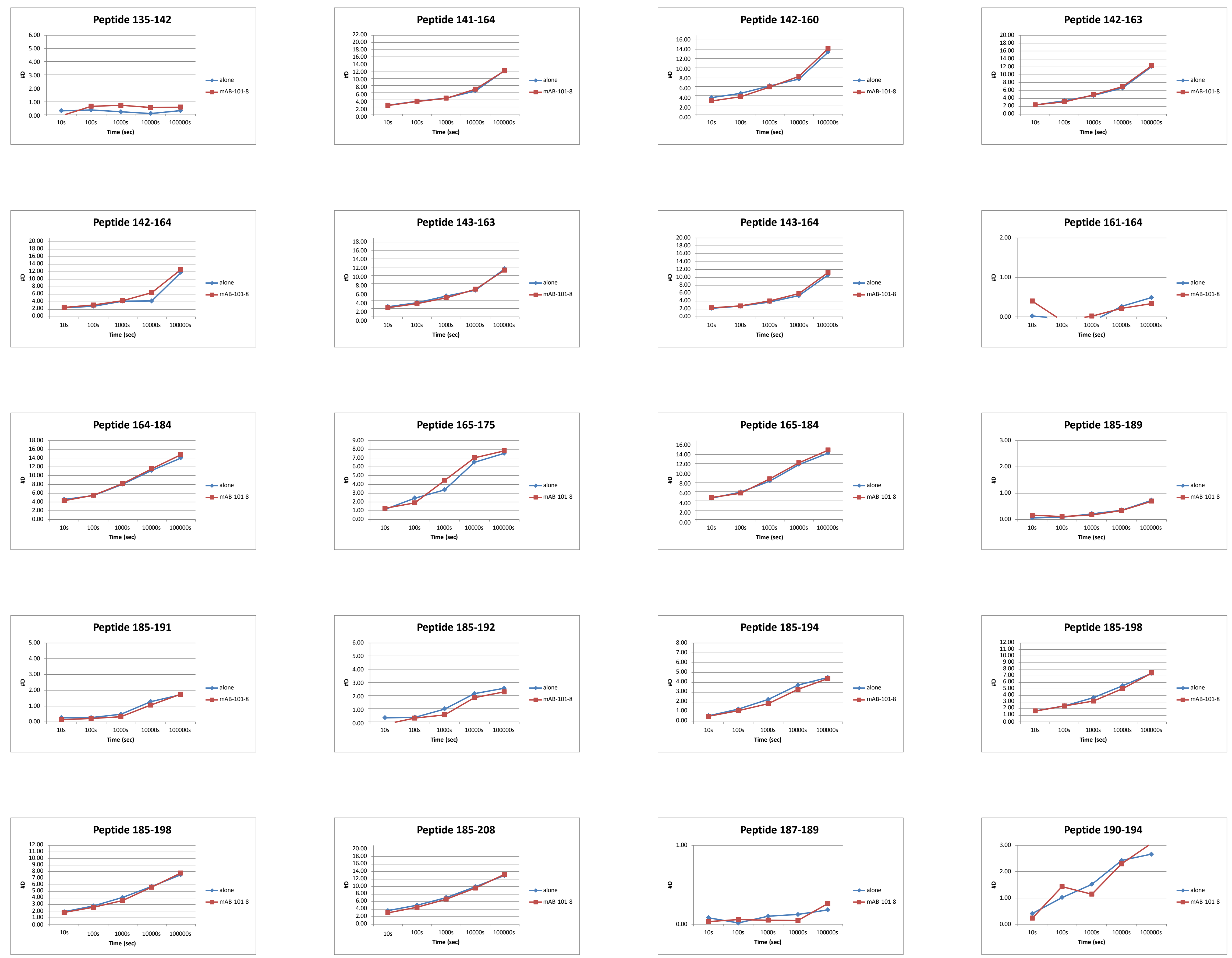

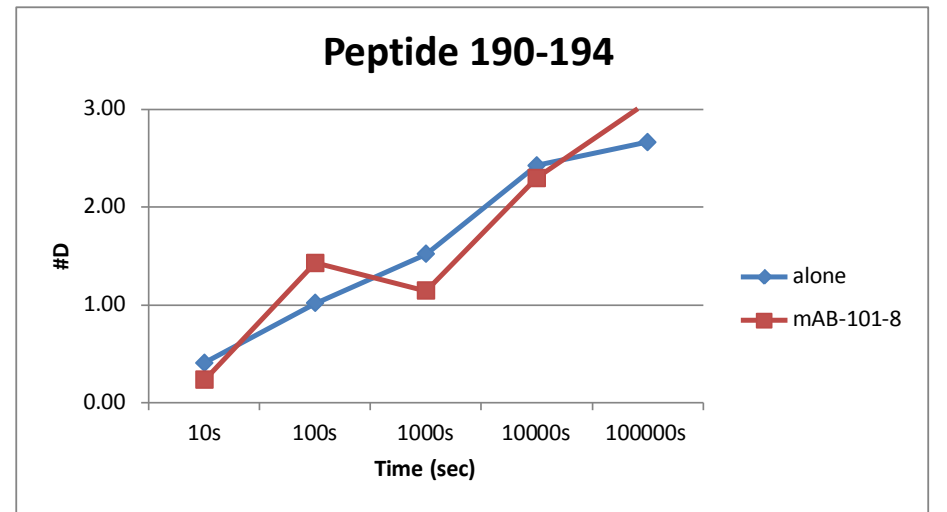




\section{SUPPLEMENTARY FIGURE 2 (CONTINUED)}
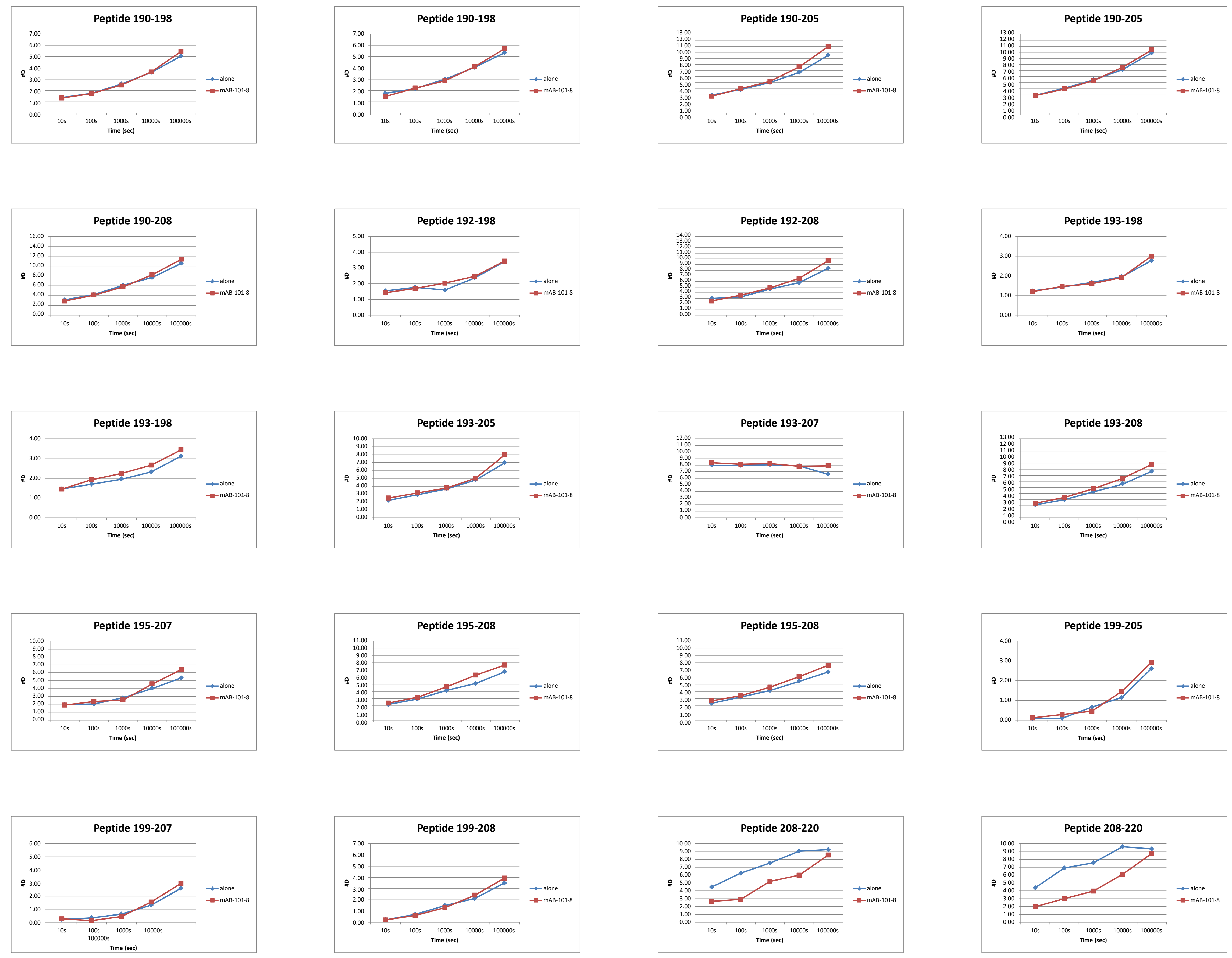

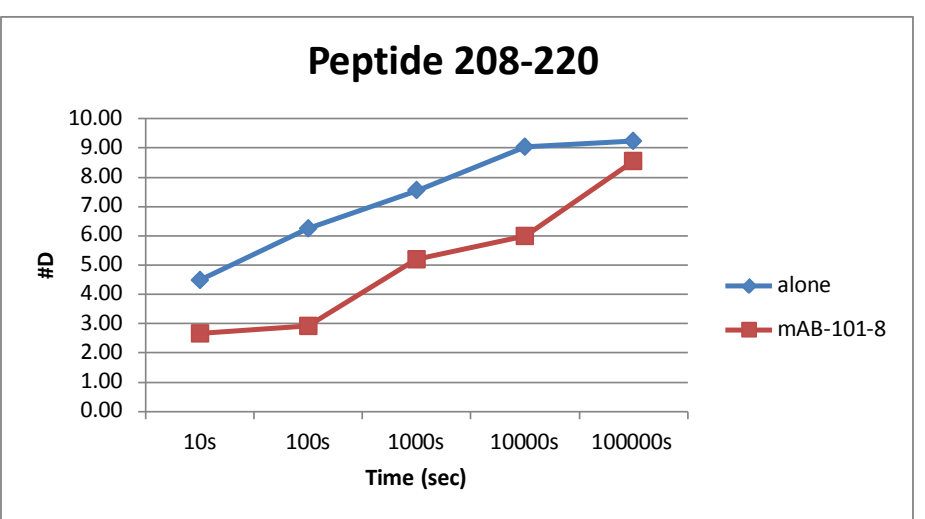




\section{SUPPLEMENTARY FIGURE 2 (CONTINUED)}
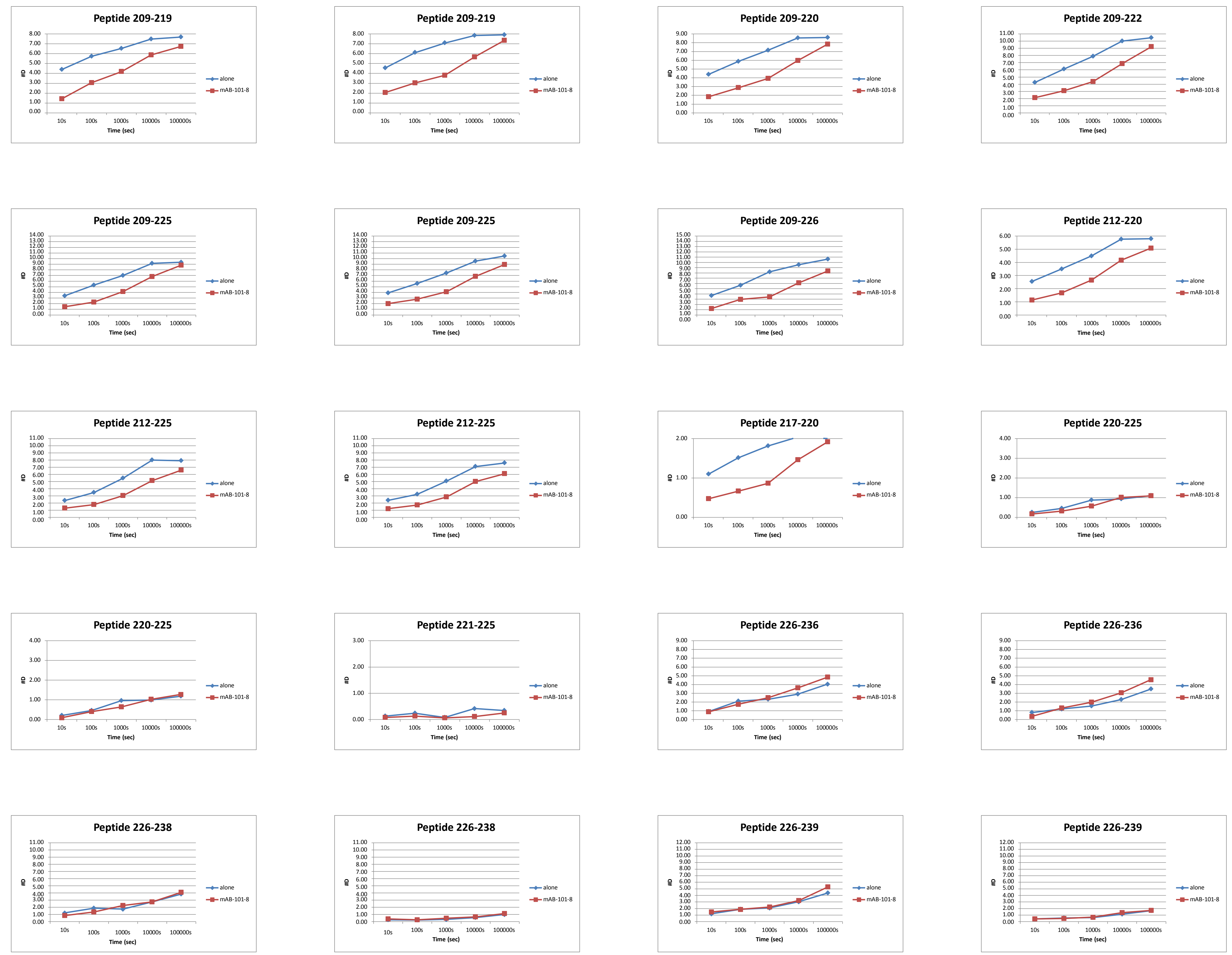


\section{SUPPLEMENTARY FIGURE 2 (CONTINUED)}
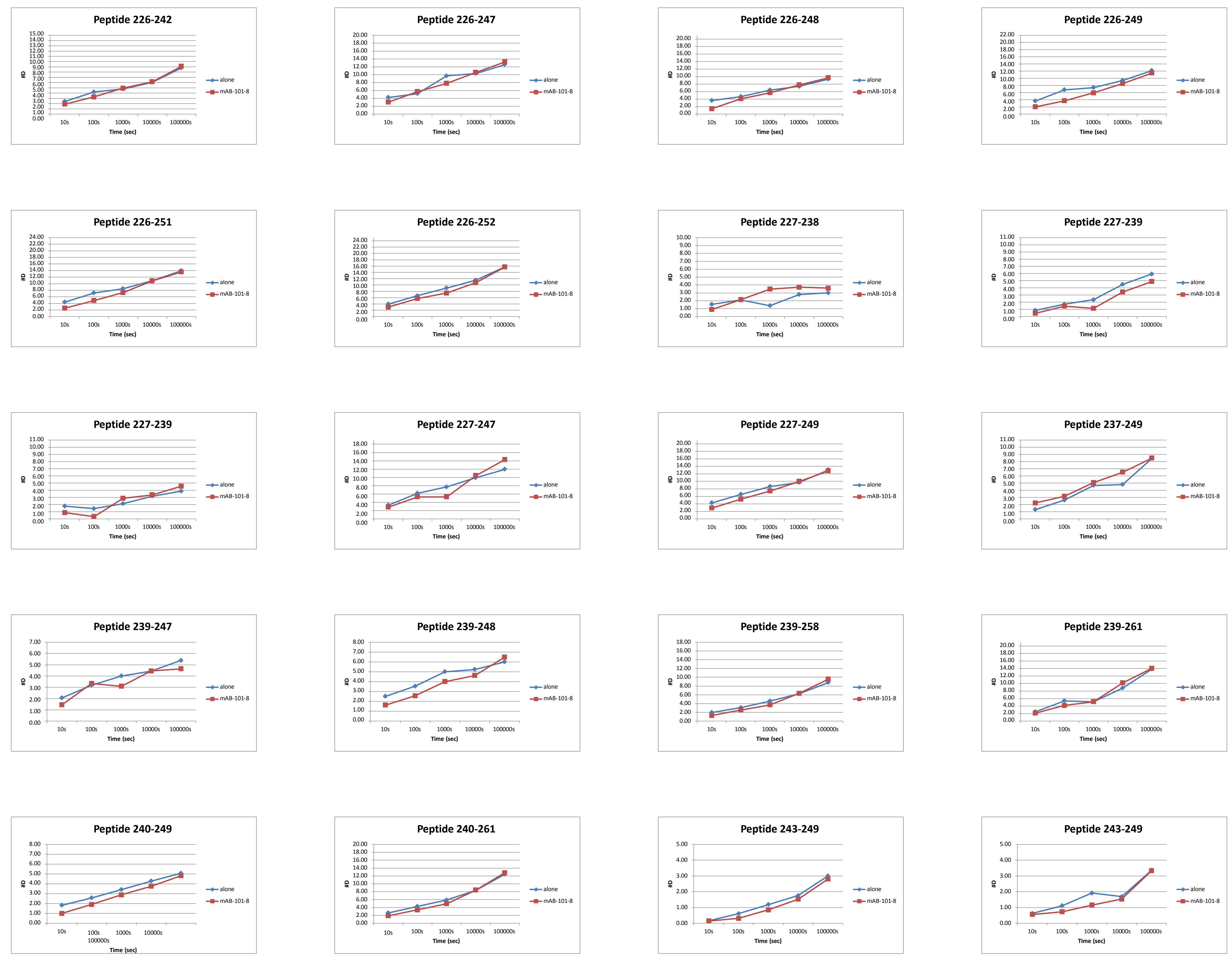

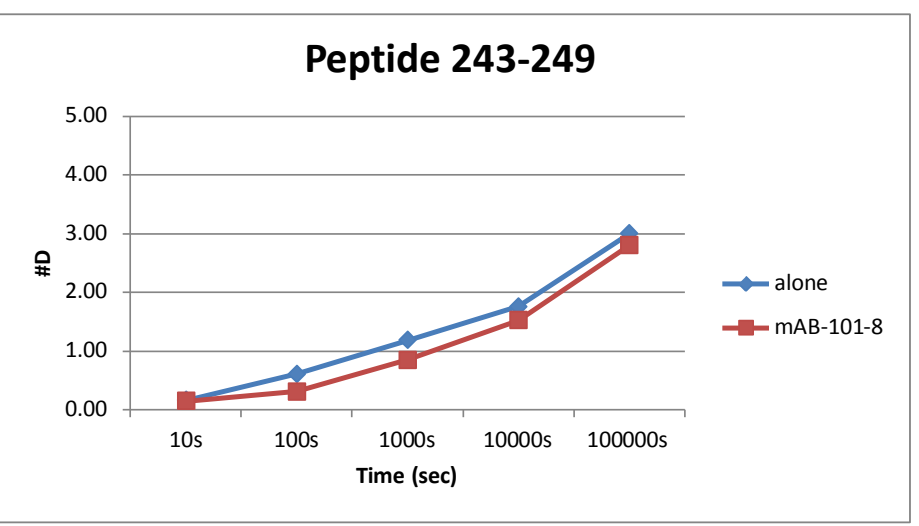




\section{SUPPLEMENTARY FIGURE 2 (CONTINUED)}
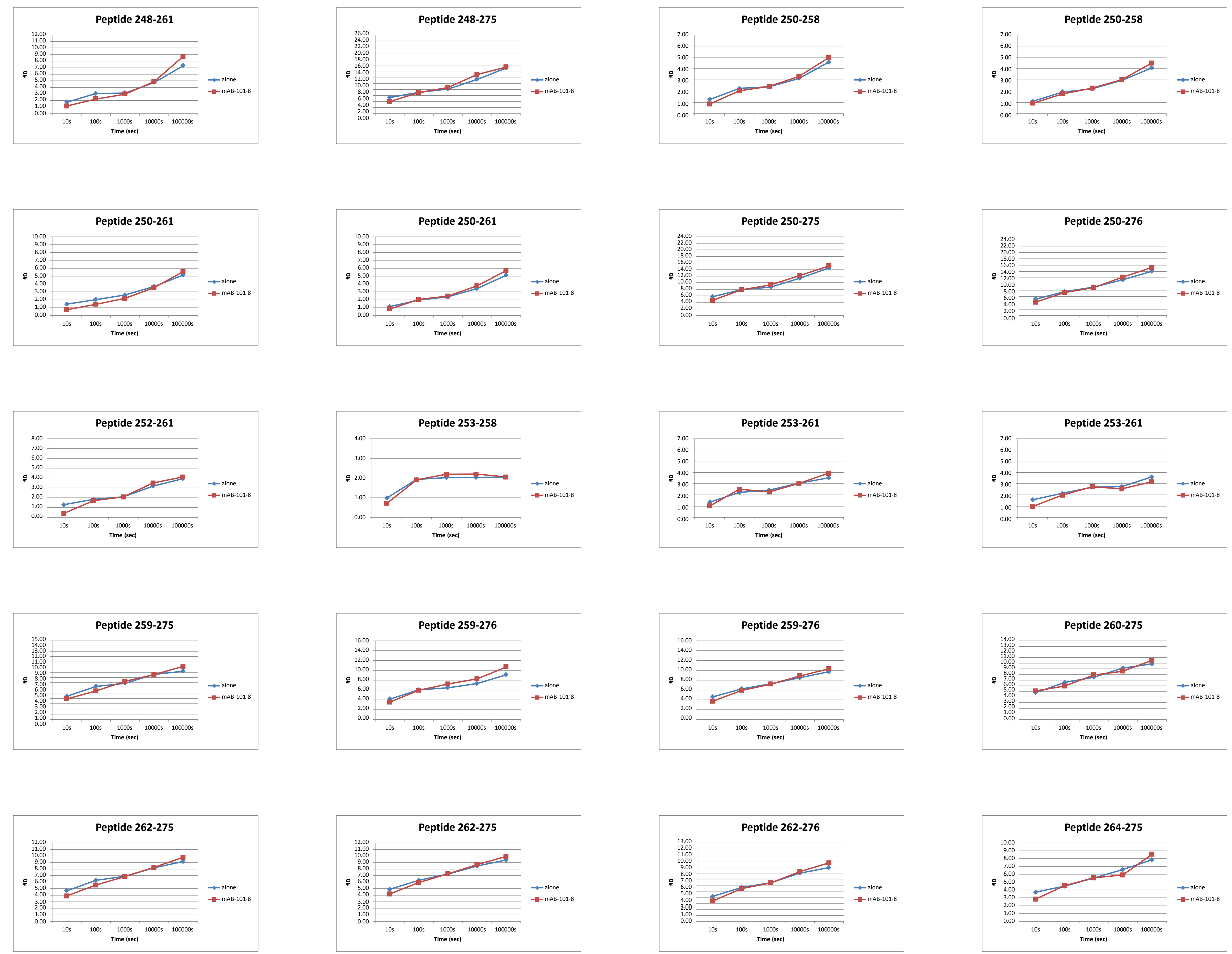

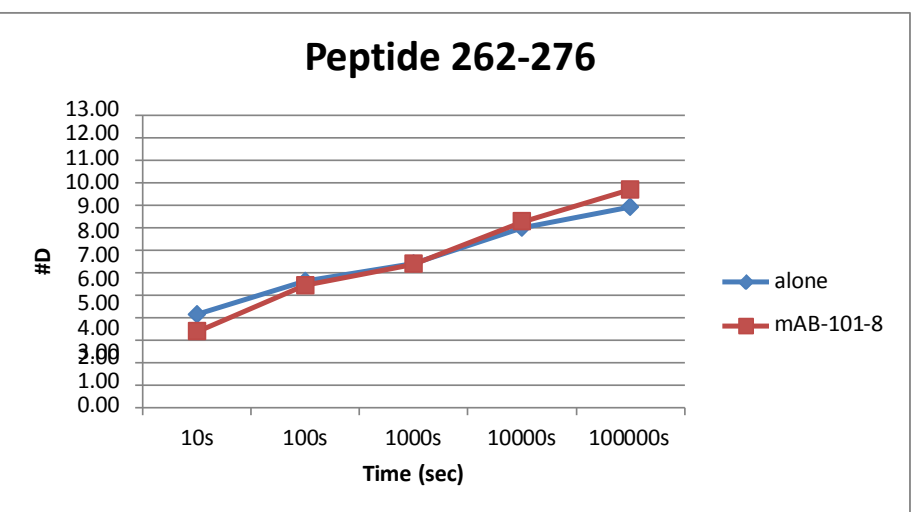


SUPPLEMENTARY FIGURE 2 (CONTINUED)
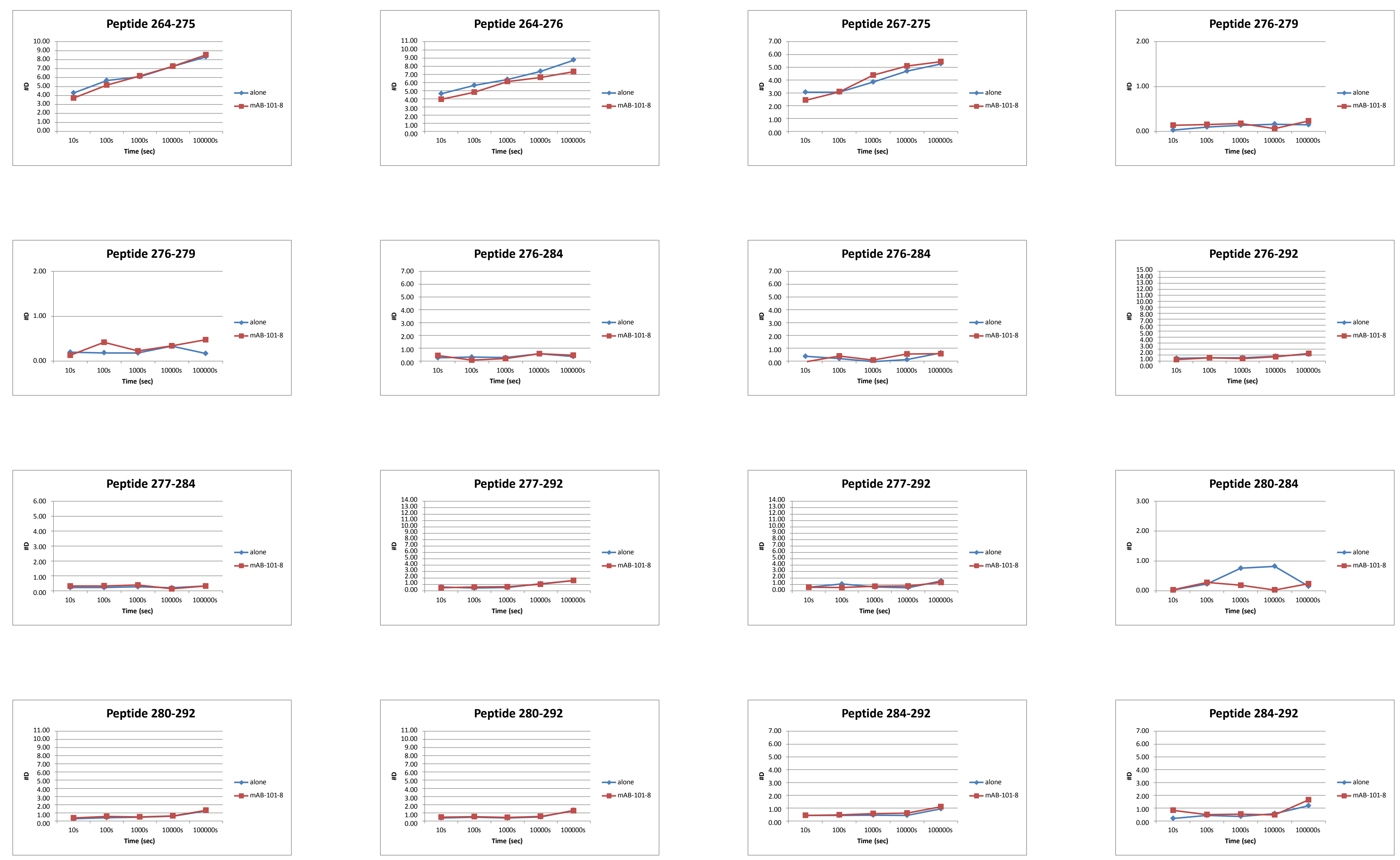
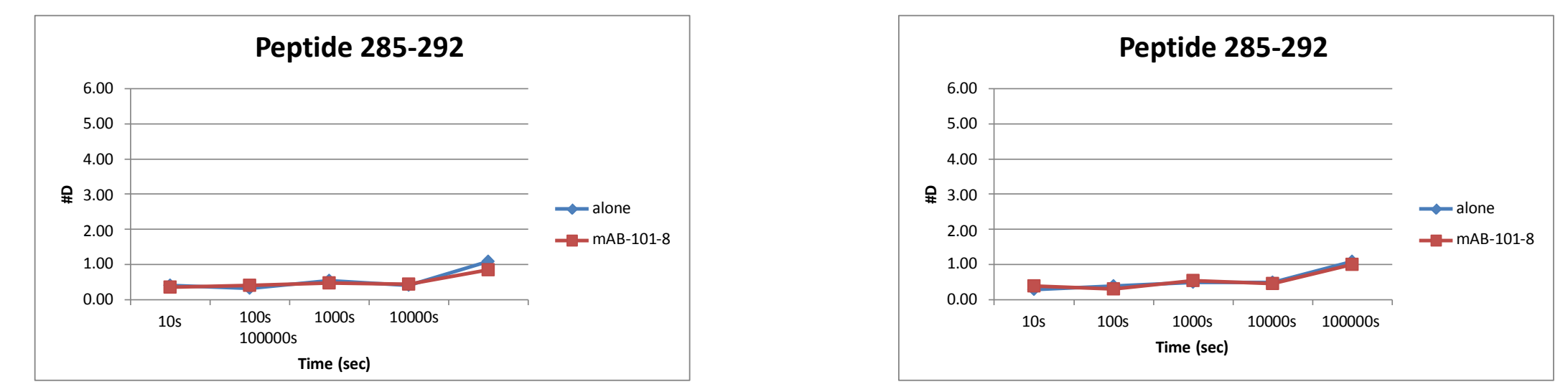